\title{
Cigarette smoking among psychiatric out-patients
}

\author{
Steve Brown, Registrar in Psychiatry, Millbrook Unit, Kings Mill Hospital, \\ Sutton-in-Ashfield, Nottinghamshire
}

The dangers of cigarette smoking are well recognised, and a number of public health measures designed to reduce the level of smoking have been introduced over the past 20 years. These measures have been fairly successful, and there has been a steady decline in the prevalence of cigarette smoking in the UK over the period 1972-1988 (Office of Population Censuses and Surveys, 1990). A number of studies have shown a higher prevalence of cigarette smoking among psychiatric patients (Hughes et al, 1986); however, the majority of these have been of highly selected populations, or have failed to control for factors such as age, sex, socioeconomic status and alcohol abuse, all of which are known to affect the prevalence of smoking. This study compared the prevalence of cigarette smoking among a heterogeneous group of psychiatric out-patients with that of the general population with control for these confounding variables.

\section{The study}

Two hundred consecutive attenders at a general adult psychiatric out-patient clinic at a district general hospital were asked to complete a questionnaire about their smoking habits. The questionnaire was a copy of that used in the 1988 General Household Survey, and was self-administered, except in the case of 11 patients who were illiterate and were helped by the reception staff. Cigarette smokers were identified as those who answered yes to the question: "Do you smoke cigarettes now?". Further questions enquired into the smoking history, demographic details and attitudes to smoking. $\chi^{2}$ analysis was used to compare the responses of the patient group with the results from the 1988 General Household Survey (Office of Population Censuses and Surveys, 1990).

One hundred and ninety-one patients completed the questionnaire (94 male and 97 female). The mean age of the men was 45.3 years (C.L. 42.5-48.0 years), the women were slightly older at 54.2 years (C.L. 51.5-56.9 years). The patients were drawn from a predominantly mining community, with an excess of manual workers, $\left(\chi^{2}=24.9\right.$, d.f. $\left.=5, P<0.01\right)$. The level of unemployment was extremely high, with only $32 \%$ of the men and $23 \%$ of the women of working age in work at the time of the study.
TABLE I

Prevalence of cigarette smoking in the psychiatric patients and the general population

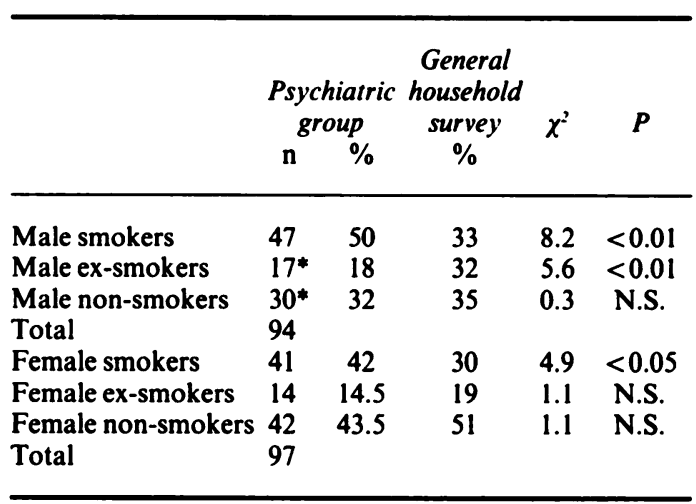

*Includes 4 cigar/pipe smokers.

**Includes 1 pipe smoker.

The prevalence of cigarette smoking among the psychiatric patients was about one and a half times that of the general public, both among the men $(50 \%$ v. $33 \% \chi^{2}=8.2$, d.f. $\left.=1, P<0.01\right)$ and the women (42\% v. $30 \% \chi^{2}=4.9$, d.f. $\left.=1, P<0.05\right)$. The higher prevalence was present in all age groups and socioeconomic classes, and remained when those with a history of substance abuse had been excluded from the figures. The mean duration of smoking was 28.3 years (C.L. 12.1-44.5 years).

The mean number of cigarettes smoked each week was higher in the patient group, both among the men (168, C.L. $140-196$ v. $120, t=3.81$, d.f. $=1, P<0.1$ ) and the women $(132$, C.L. $114-150$ v. $99, t=3.77$, d.f. $=1, P<0.1$, and significantly fewer smoked low tar (tar yield $<10 \mathrm{mg} /$ cigarette) brands of cigarette $\left(8 \%\right.$ v. $20 \% \chi^{2}=12.8$, d.f. $=1, P<0.01$ ).

An interesting finding was that while similar numbers in each group had smoked at some time in their lives, significantly fewer of the psychiatric patients had managed to give up smoking $(25.5 \% \mathrm{v}$. $16.5 \% \chi^{2}=6.6$, d.f. $\left.=1, P<0.01\right)$. This difference was especially marked among the men. Just over half of the group expressed concern about the dangers of cigarette smoking, and a similar proportion claimed to have seriously tried to give up smoking at some time in the past. 


\section{Comment}

The results of this study almost certainly represent a real difference in the smoking behaviour of psychiatric patients compared to the general public, and confirm similar findings from the USA (Hughes et al, 1986). The patients were all living in the community at the time of the study; the findings cannot therefore be attributed to the effects of institutionalisation. It is possible that the patients were drawn from a community with an atypical pattern of smoking; however the prevalence of cigarette smoking in the East Midlands is actually slightly lower than the national average (Wald et al, 1988).

The health risks posed by cigarette smoking exceed those of a number of other problems of substance abuse that are regarded as the province of the psychiatrist. These risks can be greatly reduced by stopping smoking (Friedman et al, 1981). This is something that the patient group seemed to have failed to do. There are a number of possible explanations of this finding; however, one hypothesis would be that cigarette smoking is not regarded as being an important problem in people with serious psychiatric illness and it is therefore ignored.

Knowledge of a patient's smoking behaviour is also important to the psychiatrist at an individual level as it may complicate assessment and treatment. Smoking can reduce anxiety, while abstinence may produce symptoms such as anxiety, irritability and overeating. Nicotine is a powerful drug with effects on neurotransmitter systems and on the action of psychotropic drugs.

General practice studies have demonstrated that a relatively brief intervention by the doctor can lead to a significant reduction in the level of smoking (Russell et al, 1979). The psychiatrist is well placed to make such an intervention. All the patients in this study were well enough to understand simple advice and instructions. Cigarette smoking is highly dangerous behaviour, both to the smoker and on occasions to others, such as the victims of fires caused by discarded cigarette ends. I would argue that we have a responsibility to offer help in this area, and that we should also give some thought to our responsibilities as role models.

\section{Acknowledgements}

I would like to thank Dr Brian Ferguson for his help and advice, and also the staff of Millbrook Unit reception area for their immense helpin administering the questionnaire.

\section{References}

Friedman, G. D., Petitti, D. B., Bawol, R. D. \& Sieglaub, A. B. (1981) Mortality in cigarette smokers and quitters. New England Journal of Medicine, 304, $1407-1410$.

Hughes, J. R., Hatsukami, D., Mrtchell, J. E. \& DAHLGREN, L. A. (1986) Prevalence of smoking among psychiatric out-patients. American Journal of Psychiatry, 143, 993-997.

Office of Population Censuses and Surveys (1990) O.P.C.S. Monitor SS90/2.

Russell, M. A. H., Wilson, C. \& TAYLoR, C. (1979) Effects of general practitioner advice against smoking. British Medical Journal, ii, 231-235.

Wald, N., Kiryluk, S., Darby, S., Doll, R., Pike, M. \& Peto, R. (1988) UK Smoking Statistics. Oxford University Press, pp. 147, 192-196. 